Please quote as: Winkler, R.; Briggs, R. O.; de Vreede, G. -J.; Leimeister, J. M.; Oeste-Reiss, S. \& Söllner, M. (2020): Modeling Support for Mass Collaboration in Open Innovation Initiatives-The Facilitation Process Model 2.0. In: IEEE Transactions on Engineering Management. 


\title{
Modeling Support for Mass Collaboration in Open Innovation Initiatives-The Facilitation Process Model 2.0
}

\author{
Rainer Winkler ${ }^{\circledR}$, Robert O. Briggs, Gert-Jan de Vreede, Jan Marco Leimeister, Sarah Oeste-Reiss, \\ and Matthias Söllner (i)
}

\begin{abstract}
Many governments and organizations recognize the potential of open innovation (OI) models to create value with large numbers of people beyond the organization. It can be challenging, however, to design an effective collaborative process for a massive group. Collaboration engineering (CE) is an approach for the design and deployment of repeatable collaborative work practices that can be executed by practitioners themselves without the ongoing support of external collaboration engineers. To manage the complexity of the design process, they use a modeling technique called facilitation process models (FPM) to capture high-level design decisions that serve different purposes, such as documenting and communicating a design, etc. FPM, however, was developed to support designs for groups of fewer than 100 people. It does not yet represent design elements that become important when designing for groups of hundreds or thousands of participants, which can be found in many OI settings. We use a design science approach to identify the limitations of the original FPM and derive requirements for extending FPM. This article contributes to the $\mathrm{CE}$ and to the OI literature by offering an FPM 2.0 that assists CE designers to design new OI processes, with a special focus on outside-in OI.
\end{abstract}

Index Terms-Collaboration, collaborative work, crowdsourcing, process modeling.

\section{INTRODUCTION}

M ANY governments and organizations recognize the potential of open innovation (OI) models to involve large numbers of people beyond the boundaries of their organization. However, setting up sustainable, repeatable OI initiatives is no trivial task [1]. A critical challenge that organizational leaders face concerns the organization and management of the crowd's collaboration process in terms of idea generation, convergence, evaluation, and selection [2]-[4]. There are many considerations

Manuscript received March 31, 2019; revised August 30, 2019 and November 7, 2019; accepted February 8, 2020. Review of this manuscript was arranged by Department Editor R. D. Evans. (Corresponding author: Rainer Winkler.)

Rainer Winkler and Jan Marco Leimeister are with the University of St. Gallen, St. Gallen 9000, Switzerland (e-mail: rainer.winkler@unisg.ch; janmarco.leimeister@unisg.ch).

Robert O. Briggs is with San Diego State University, San Diego, CA 92182 USA (e-mail: rbriggs@mail.sdsu.edu).

Gert-Jan de Vreede is with the University of South Florida, Tampa, FL 33612 USA (e-mail: gdevreede@usf.edu).

Sarah Oeste-Reiss and Matthias Söllner are with the University of Kassel, 34127 Kassel, Germany (e-mail: oeste-reiss@uni-kassel.de; soellner@unikassel.de).

Digital Object Identifier 10.1109/TEM.2020.2975938 to be taken into account, including but not limited to different stakeholders that are required for the initiative, expected inand outputs to create a successful group product in the end, the process that the OI project has to follow to reach its goals and produce the desired deliverables, and the moderation of the crowd and the internal staff so that there is sustained and purposeful participation throughout the project. In short, an OI project requires 1) dedicated design effort before it can be initiated and 2) dedicated supervision to ensure that it continues to make acceptable progress toward a high-quality outcome.

Unfortunately, the field of OI research is still relatively young and does not offer much in the way of guidance and techniques on how to design and manage OI efforts so that the purported benefits may be achieved repeatedly across a large number of structurally comparable initiatives [5]. The purpose of our research is to develop a modeling technique that can support organizers of OI projects to document and communicate their process designs such that these designs can serve as guidance during the execution of the projects as well as become a foundation for future, structurally comparable projects.

We thereby respond to the call of Chesbrough et al. [6], where they state that our current understanding of a firm's processes for participating in OI projects is scattered and limited. Our research is grounded in several theoretical perspectives. The core foundation is provided by the work of Alexander and colleagues on design best practices (called design patterns) and the work of de Vreede, Briggs, and colleagues on collaboration engineering (CE). Alexander et al. [7] proposed design patterns as a mechanism to improve the efficiency and quality of a design process in architecture. Their work inspired the area of CE research. CE) is an approach for the design and deployment of repeatable collaborative work practices that can be executed by practitioners without the ongoing support of external collaboration engineers [8]. In CE, a collaboration engineer designs a collaborative work practice in such a way that practitioners can execute it by themselves with little or no training in either the tools or the techniques. Thus, a collaboration engineer creates "leave-behind" collaboration process designs. Practitioners are domain experts without significant facilitation experience, trained to become experts in conducting one specific collaboration process. They execute the designed collaboration process as part of their regular work [8]. They neither have the skills nor the expertise to design novel collaborative work practices. 
A key design activity in CE concerns modeling collaborative work practices. For this purpose, $\mathrm{CE}$ researchers and practitioners have used a modeling technique called facilitation process model (FPM) that aims to design collaborative work practices. However, this modeling technique suffers from several shortcomings when it comes to modeling mass collaborations such as visualizing unmoderated activities or different stakeholder groups. The rest of the article is organized as follows.

Section II provides a theoretical background. Research methodology is given in Section III. Section IV describes a design science research approach to identify the main challenges with the original FPM technique derive and evaluate requirements (see Sections IV-B-IV-D), and design a revised modeling technique that is based on the current technique enriched by some Business Process Model and Notation (BPMN) 2.0 elements (see Section IV-E). BPMN 2.0 has become a leading standard for business process modeling, offering elements that are able to serve for our modeling technique [9]. We illustrate and evaluate the application of the revised FPM technique in an exemplary OI scenario (see Sections IV-F and IV.G). Section V provides a discussion of our study. Finally Section VI concludes the article. This article contributes to both the OI and CE literature by offering a revised FPM technique that assists designers and practitioners to capture new forms of mass collaborations, such as OI projects, with a special focus on outside-in $\mathrm{OI}$ endeavors.

\section{THEORETICAL BACKGROUND}

\section{A. Collaboration Engineering}

$\mathrm{CE}$ is an approach to design collaborative work practices for high-value recurring tasks and to deploy them to facilitators (noncollaboration experts) who can execute them with no training in tools and techniques [10]. Purposes and characteristics of $\mathrm{CE}$ are to minimize the cognitive load for the facilitators that join and execute a collaborative work practice (e.g., they will be able to focus on the task to be solved and not on how to develop ad-hoc collaboration like building groups). In addition, a collaborative work practice packages collaboration expertise with facilitation skills and knowledge about group dynamics and collaboration technology in a way that a facilitator can execute it [10]. The CE approach results in a number of artifacts that represent the design of a collaborative work practice. These artifacts are used as vehicles of communication among designers and between designers and stakeholders. For example, they are used to present collaboration processes to organizations and to support the training of facilitators (noncollaboration experts) who will execute the CE processes [11]. Since the early 2000s, $\mathrm{CE}$ researchers have developed various techniques to develop, model, and document repeatable collaborative work practices. For developing collaborative work practices, the six-layer model as well as the collaboration process design approach provide procedures on how to iteratively develop and test a collaborative work practice [12], [13]. For modeling and documenting collaborative work practices, so-called thinkLets and the facilitation process model (FPM) are used. ThinkLets are bundled facilitation techniques that codify facilitation skills to achieve predictable, repeatable patterns of collaboration (i.e., generate, reduce, organize, evaluate, build consensus [14]). A thinkLet specifies the facilitator's choices and actions within an activity of FPM, the configuration of this tool, and scripted prompts to accomplish a pattern of collaboration in a group. The aim of thinkLets is to help facilitators conduct their activities. They can be considered as general building blocks that help facilitators to develop and transfer repeatable collaborative work practices [15]. The so-called FPM is a modeling technique with the help of which we can capture the logical flow of a process in terms of its procedure of activities. It offers various elements and rules for modeling a collaborative work practice [11].

Researchers identified two unique roles in CE: Participants (e.g., the crowd) and a facilitator. The participants execute the process that the facilitator has designed and moderates. Facilitators can be considered as collaboration engineers, who design a collaboration process in such a way that practitioners can execute it by themselves with little or no training in either the tools or the techniques. Practitioners are domain experts, who are not collaboration engineers but who are in charge of executing a collaboration process. Examples of practitioners are risk managers who conduct risk assessments, the crowd who provides ideas, etc. There has been a steady stream of publications that report on professional applications of the CE approach and its concepts [16]-[20]. For example, van Grinsven and van de Vreede implemented a CE approach for a distributed collaborative risk management process and piloted it in a multinational service organization, an insurance company, and an international financial institution. The process was considered to be effective by company experts [21]. Noor et al. [22] proposed a collaborative product line scoping approach for a reengineering-based product line adoption based on guidelines from CE. This approach helped to increase process productivity and effectiveness. Giesbrecht et al. [23] used CE concepts to empower service agents to put value co-creation into practice. A test with employees in a public administration's front office has provided evidence that $\mathrm{CE}$ can effectively empower service agents on the job to adapt their work practices and to bring value co-creation into practice.

\section{B. Facilitation Process Model}

As introduced above, the FPM is a modeling technique that captures high-level design decisions to illustrate the logical flow of the procedure of activities of a collaborative work practice on a meta level [15]. Specifically, an FPM captures relevant information about two key aspects: the activities itself and the flow between these activities.

1) For each activity, the following information is captured: the activity's name; the pattern of collaboration ${ }^{1}$ that will be satisfied by executing the activity; the activity's duration; the collaborative work product that will be created while the activity is underway (output); and the name of the thinkLet that is used to execute the activity [15].

2) For the activity flow, the following information is captured: the sequence number of each activity, and decisions and

\footnotetext{
${ }^{1}$ Each activity in an FPM can result in one or more of the following patterns of collaboration: generate, reduce, clarify, organize, evaluate, and build consensus [14].
} 


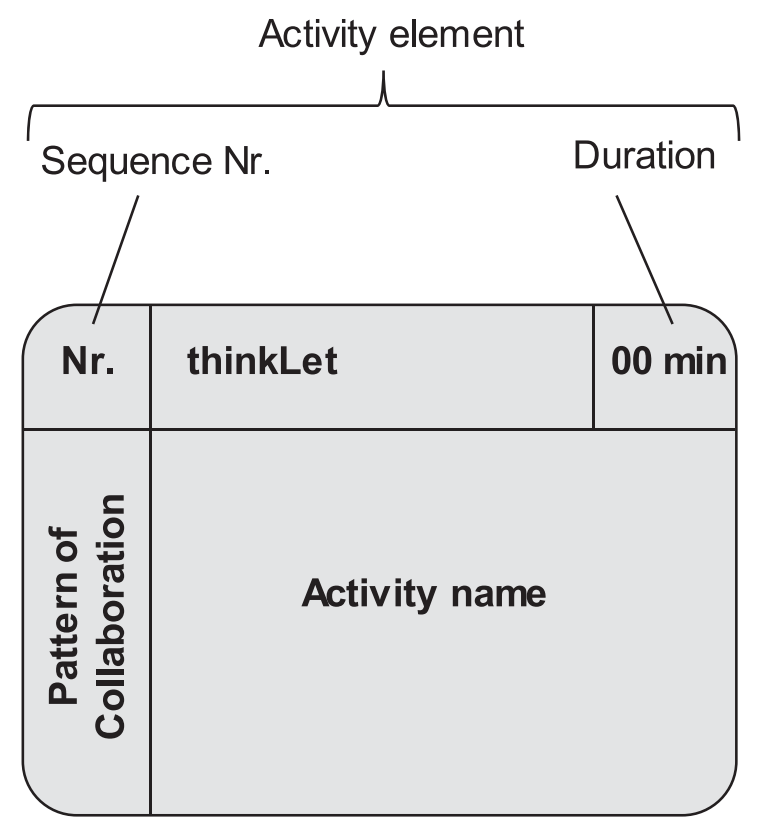

Fig. 1. FPM modeling elements [16].

decision criteria that may affect the process flow. An FPM represents each activity as a rectangle with rounded corners that has been divided into five fields (see Fig. 1).

Consequently, the FPM illustrates a brief overview of a collaborative work practice. In this light, the FPM is a modeling technique that follows the main goal of creating an overview of a designers' developed collaborative work practice in the form of a process model that captures their high-level design decisions [16]. Thus, the toolkit of the FPM should help the modeler to express their design knowledge for the collaborative working practice [24].

An example of an FPM is given in Fig. 2; it represents a part of a Risk \& Control Self-Assessment process [10].

Participants in the risk management process identify the risk areas concerning the situation that is being addressed, prioritize the most important risks, and categorize them into the relevant themes. Finally, participants check the correct categorization and the meaning of each risk. If participants think that the identified risks are well developed, the next risk management process starts. Otherwise, the identification of risk areas starts again. As can be seen in Fig. 2, each activity uses a certain thinkLet that defines the tools, their configuration, and the facilitation that has to be followed to carry out the activity [21].

\section{Business Process Modeling}

A model provides a limited representation of an existing or conceptualized reality. It captures the reality's elements that are essential for the purpose of the model. Models are expressed in a modeling language (ML). An ML is any artificial language that can be used to express information, knowledge, workflows, or systems in a structure that is defined by a consistent set of elements with rules [9]. For example, every business process model requires an ML to be expressed. One of the most common ML standards in the field of business process modeling is BPMN 2.0. BPMN 2.0 was developed by the Object Management Group and was first released in 2013 [9]. BPMN 2.0 is a graphical representation for specifying business processes [25]. In recent years, BPMN 2.0 has become the leading standard for business process modeling. Many organizations are adopting BPMN 2.0 as their organization-wide modeling standard. For example, a recent survey with 150 BPM providers revealed that BPMN 2.0 was the most widely used process modeling notation and this trend is expected to continue [26]. BPMN 2.0 aims to provide a standard notation that all business stakeholders can easily understand, including the business analysts who create and refine the processes, the technical developers responsible for implementing them, and the business managers who monitor and manage them. BPMN 2.0 can therefore help to bridge the gap between business process design and implementation. The main elements used by BPMN 2.0 are pools, lanes, activities, arrows, gateways, and events that each have a description and rule for being used: The pool is a general kind of container for a complete business process. The pool can consist of different (swim) lanes that are used to model a collaboration between different actors, i.e., the interplay of several partners' processes. Each partner's process is shown in a separate lane. A rounded rectangle represents an activity. Similar to the FPM technique, an activity symbolizes that something gets done. The connecting arrows are used for modeling the sequence flow. They represent the sequence in which the different events, activities, and other elements are traversed. Activities can also be followed by a gateway. A gateway has a diamond shape and indicates that from that point onward one of several outgoing sequence flows is activated. The conditions on the outgoing flow determine which flow is selected. These conditions can be written directly into the diagram, next to the sequence flows. Finally, BPMN 2.0 uses events. Every process consists of a start event (a circle) and an 


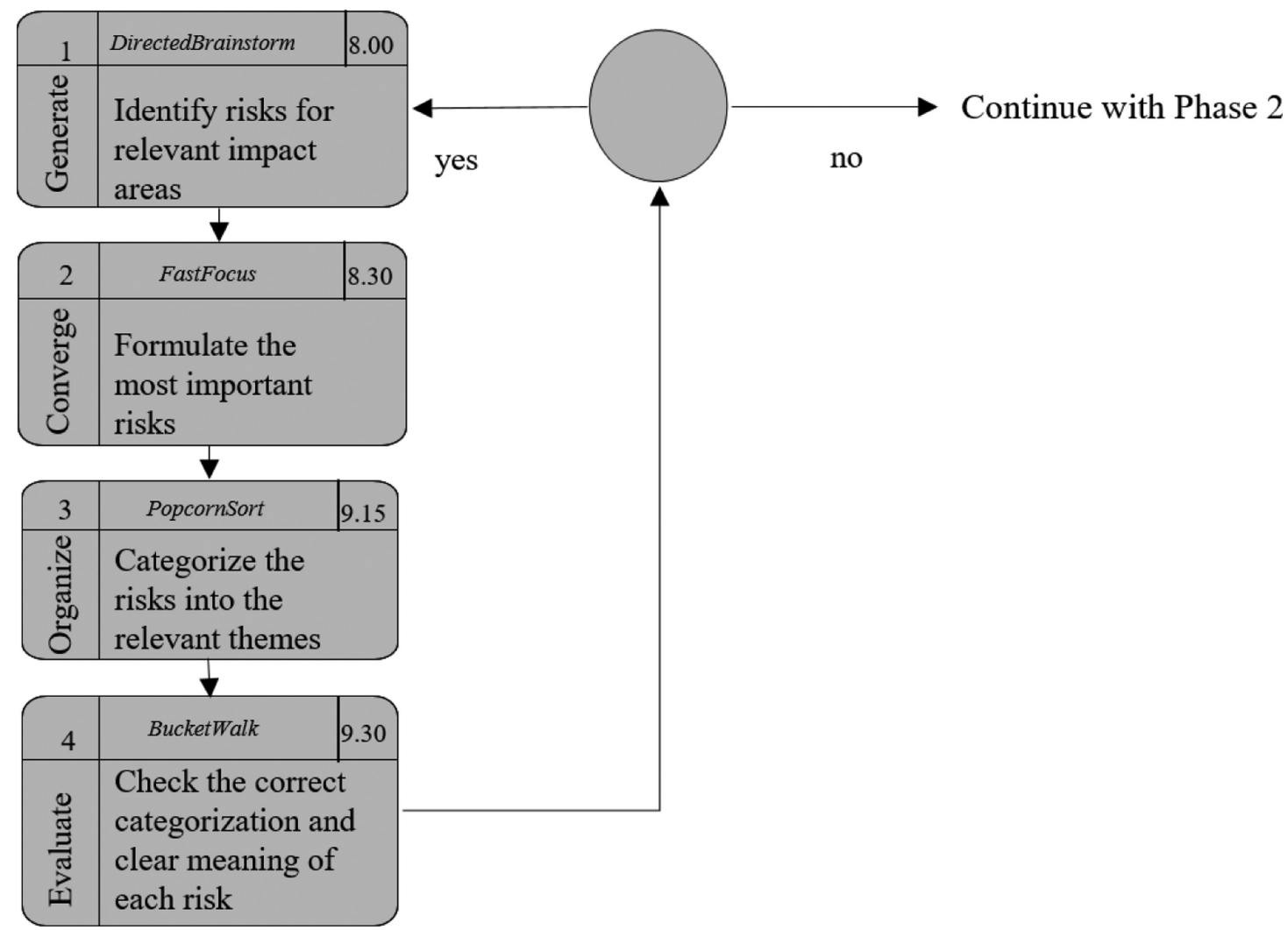

Fig. 2. FPM example.

end event (a circle with a thick border). Apart from these core elements, BPMN 2.0 consists of various constructs that assist with the visualization of complex processes in more detail.

In contrast to business processes that focus on structuring tasks in a specific sequence, collaboration processes focus more explicitly on the interaction between the different collaborators. Thus, business processes lack some important features that are necessary for designing new collaborative work practices. For example, BPMN 2.0 is not able to capture thinkLets and Patterns of Collaboration. A thinkLet describes an elementary group process from a leader's point of view by providing explicit, scripted prompts for the group and by guiding the practitioner through the decisions that must be made based on the group's behavior. By this means, people engage in a specific pattern of collaboration that cannot be visualized by BPMN 2.0. Whereas business process modeling tries to divide a process into subprocesses that pursue a particular business goal, $\mathrm{CE}$ focuses more on how individuals and subgroups have to work together within these subprocesses in order to create a common group product. Notwithstanding these differences, we will use the BPMN 2.0 modeling elements and its rules to explore the extent to which the FPM can be developed further to be able to serve as a modeling language for mass collaborations such as OI endeavors.

\section{Open Innovation as a Form of Collaborative Work Practice}

OI is a term used to promote an information age mindset toward innovation that runs counter to the secrecy and silo mentality of traditional companies. As Chesbrough [27, p. 24] states, OI is "a paradigm that assumes that firms can and should use external ideas as well as internal ideas, and internal and external paths to market, as the companies look to advance their technology." The boundaries between a company and its environment have become more permeable; innovations can easily transfer inward and outward between companies and other companies and between firms and creative consumers. Gassmann and Enkel [28] identified three archetypes of OI processes: outside-in, inside-out, and coupled. The outside-in process describes how a company's own knowledge base can be enriched through the integration of suppliers, customers, and external knowledge sourcing (e.g., crowdsourcing). The inside-out process describes the external exploitation of ideas in different markets, selling IPs and multiplying technology by channeling ideas to the external environment. And finally, the coupled process describes how outside-in and inside-out can be coupled by working in alliances with complementary companies during which give and take are crucial for success.

Piller et al. [29] define OI as “... an interactive added value in the innovation process, in which a manufacturing company works with selected customers to jointly generate innovations." This is done through targeted and above all participatory coordination of the interaction process between manufacturers and many customers and users. This definition is narrower than the one from Chesbrough [27] and focuses on an outside-in process. In our article, we follow Piller et al.'s [29] definition of an OI process, and thus limit the scope to outside-in OI for two reasons. 


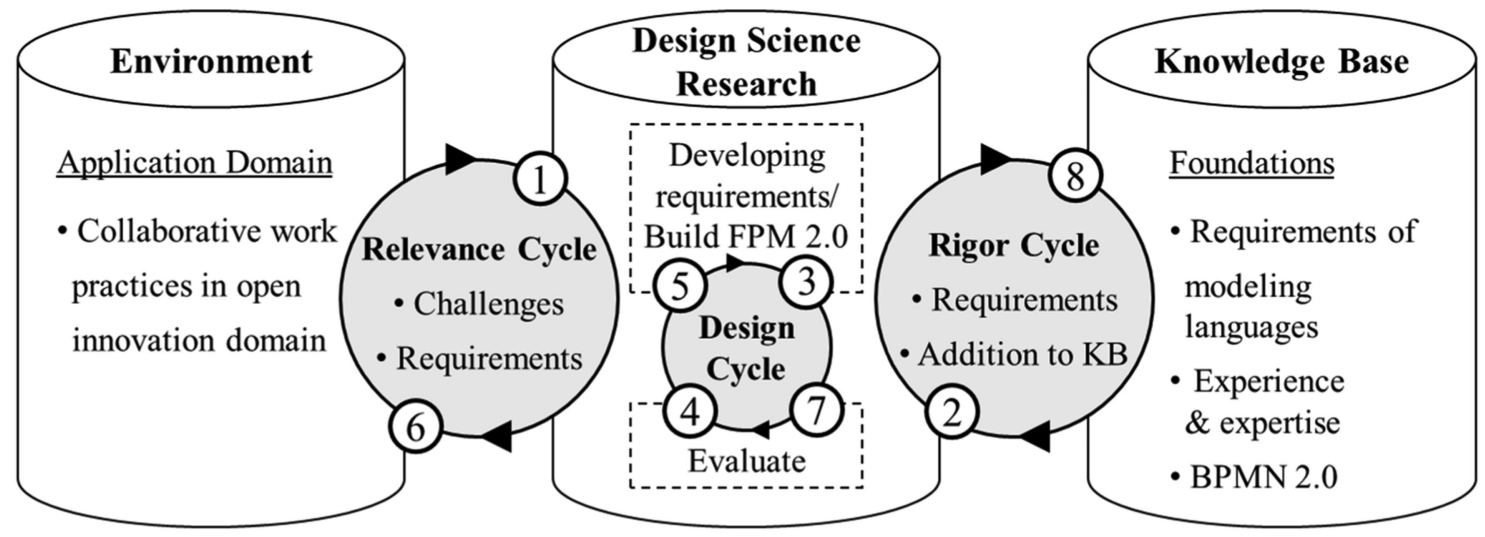
(1) Gathering challenges from practice
(2) Gathering requirements from kernel theories
(3) Formulating requirements for FPM 2.0
(4) Evaluation with CE-expert panel

(5) Developing FPM 2.0 elements

(6) Application of FPM 2.0

(7) Evaluation with OI-expert panel

8) Dissemination of FPM 2.0 as a

nascent design theory of the type improvement

Fig. 3. Research approach.

First, the described OI process can be considered as rather predictable, following a more or less structured sequence of steps (e.g., idea competition). This meets our assumption that the OI process is a repeatable collaborative work. Second, these kinds of OI projects are one of the most common types of OI projects [28]. OI goes beyond using external sources for innovation. Companies aim to build up systematic and sustainable collaborations with their external resources in order to leverage the whole potential of OI projects [30]. However, collaborating with external resources is no trivial task and requires a concentrated design effort [31]. This article should help to visualize these endeavors in a systematic way by developing a new modeling technique.

\section{RESEARCH METHODOLOGY}

We follow a Design Science Research (DSR) approach to develop FPM 2.0. More specifically, we rely on Hevner's three cycle view to structure our research process (see Fig. 3) [32].

The Relevance Cycle connects the application domain of the research project with our design science activities. The Rigor Cycle makes sure that the design science activities consider the existing knowledge base of scientific foundations, experience, and expertise. The central Design Cycle iterates between the core activities of building and evaluating our design artifact [32]. In step 1, we initiate the Relevance Cycle and outline an exemplary scenario of an OI endeavor and derive challenges we had by applying the original version of FPM. In step 2, we initiate the Rigor Cycle, where we present some general requirements from our kernel theories that serve as a foundation for FPM 2.0. In step 3, we start the Design Cycle by formulating related requirements and first solution approaches for the FPM 2.0 technique.
In step 4, we conduct a first evaluation of our requirements with a CE-expert panel. In step 5, we use our initial requirements together with the feedback from the CE-expert panel to develop FPM 2.0 elements that address the corresponding requirements. In step 6, we apply FPM 2.0 to our exemplary scenario (step 1) to show the real-world usefulness of FPM and to close our Relevance Cycle. In step 7, we conduct a second evaluation of FPM 2.0 with an OI-expert panel. This activity marks the end of our Design Cycle. In step 8, we discuss our results and our contribution that resembles a nascent design theory of the type "improvement" as it provides a new modeling technique for mass collaborations [34], [35]. Thereby we close our Rigor Cycle.

\section{FPM 2.0 DEVELOPMENT}

Emerging trends of mass collaboration settings have confronted companies with new challenges. One example of these mass collaboration settings is OI models. OI initiatives allow combining the companies' resources with external co-operators. Some organizations have gained major benefits from OI. For example, Procter \& Gamble has set the goal to produce at least $50 \%$ of their innovations from external ideas. They introduced their own platform called 'Connect \& Develop' to collaborate with their external crowd and manage new ideas [35]. Following that idea, we created a scenario that shows an exemplary OI project. We thereby address the relevance cycle of Hevner's [32] three-cycle view of DSR.

\section{A. Open Innovation Scenario}

Driven by technological advances, new forms of collaboration arise. These fast advances create the basis for mass collaboration, where hundreds or thousands of people can work together 
independent from time and place. For organizations, this raises challenges to remain competitive on the market and/or to achieve a competitive advantage. For example, in the context of crowdsourcing and OI, organizations become empowered to outsource tasks by an open call via the internet and recruit external workers for their purposes [36]. While some organizations have had great successes with OI projects, others have failed. Nevertheless, the way the stakeholders collaborate with each other is still an unsolved challenge. In addition, the challenge increases the more the advances in artificial intelligence (AI) increase. In the future, next to human teammates, there will be nonhuman teammates as well, who will join and support the collaboration [37].

\section{Scenario: The KTS Company}

The "KTS Company" is a lifestyle travelling brand that aims to leverage the potentials stemming from the technological advances that create the foundations for new forms of collaboration, such as the possibilities to enhance collaboration among hundreds or thousands of people. In particular, the KTS Company aims to initiate a new collaboration structure to support the research and development department. For this purpose, the KTS Company aims to bring together external stakeholders (e.g., customers) with the research and development department. For this purpose, the KTS Company will launch an OI project and hired a Collaboration Engineer to develop a collaborative work practice for the OI project: The OI project is an idea competition. In order to design a collaborative work practice that will have the potential to facilitate collaboration among the stakeholders (research and development department of the KTS Company as well as customers), the Collaboration Engineer conducted a stakeholder analysis and defined a collaboration goal. The collaboration goal is to create and select the best idea concept for a new lifestyle travelling hotel group that will have the highest likelihood of a competitive advantage. In an AI-supported collaboration setting [human and nonhuman teammates (i.e., artificial intelligence inherent in a text mining system)], the involved stakeholder (i.e., decision-makers and employees from the research and development department; potential customers inherent in crowd workers) will create and select the best idea concept during the next five weeks. The general collaboration process consists of the following four phases:

1) ideation phase;

2) convergence phase;

3) evaluation phase;

4) selection phase.

1) In the Ideation Phase, the decision-makers of the KTS Company generate an assignment for their employees and customers (external crowd workers). The assignment specifies the categories for which they want to collect new idea concepts. In the subsequent activity, employees and external crowd workers generate ideas independently from each other. While the employees can start directly, the crowd workers need to complete an aptitude test. Both stakeholders are instructed to complete their task within one week, resulting in a collaborative work product as an unsorted list of idea results.

2) In the Convergence Phase, the unsorted list of ideas is delivered to an AI (i.e., text mining system) that uses machine learning techniques to identify and cluster similar ideas into a list of 80 ideas. After that, the AI delivers the cleaned list of ideas to the group of decision-makers. After the ideas are entered into the database, the AI system autonomously compares similar contributions and clusters them together. These clusters are then sent to the other stakeholders, resulting in a list of around 80 different ideas.

3) In the Evaluation Phase, decision-makers evaluate the ideas and build a list of the top $25 \%$ of ideas. Next, the top $25 \%$ of ideas are split into subsets and are assigned to smaller breakout groups of employees. Those breakout groups work in parallel and elaborate the assigned ideas to meaningful idea concepts. The idea concepts constitute the input for the next phase and activity.

4) Finally, the Selection Phase starts in which the decisionmakers evaluate the top $25 \%$ of idea concepts based on pre-defined criteria and select the best idea.

The scenario described above exemplarily illustrates key challenges that a Collaboration Engineer needs to cope with in order to model a collaborative work practice.

1) Challenge 1-Different team compositions: OI projects have different stakeholder groups. In our scenario, the team consists of decision-makers, employees, and crowd workers that execute different activities.

2) Challenge 2-Partial Activities with deadlines: Different stakeholders are sometimes working on different pieces of an activity, resulting in a collaborative work product. In our scenario, the crowd workers as well as the employees have to finish their piece of an activity (generating ideas) within one week.

3) Challenge 3-Different Workspaces: Collaborative working practices such as in OI projects require stakeholders to work in different workspaces. In our scenario, crowd workers and employees work together on a shared writing page.

4) Challenge 4-External Input for Activities: Some activities can only be executed if a team is provided with additional information that comes from an external source. In our scenario, decision-makers need evaluation criteria from outside in order to evaluate the top ideas.

5) Challenge 5 (included after evaluation)_Parallel Activities. A collaboration process may require a number of activities to be executed in parallel and completed before a next activity can commence. In our scenario, employees have to split up into subgroups for developing different idea concepts.

\section{B. General Requirements Arising From New Forms of Collaboration}

Collaboration engineering researchers are now working on how to design mass collaboration processes to be as predictable and transferable as engineered work practices for small-scale 
collaborations and on how to model the collaborative work practice using the FPM. By applying the original version of FPM for our exemplary scenario, we discovered the key challenges mentioned in the section before. Driven by these challenges, we are now able to derive generalizable requirements (GR) for a revision of the FPM.

First, FPM 1.0 is not able to visualize different team compositions that are very common in OI projects. For example, the current FPM technique is not able to show practitioners which kind of activities employees or the crowd have to conduct. Therefore

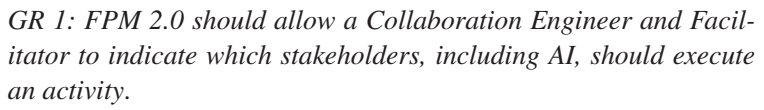

Second, FPM 1.0 is not able to indicate activities outside of face-to-face meetings that will be executed by a stakeholder group on their own as a part of the creation of a collaborative work product. This also includes the visualization of deadlines for these subproducts. For example, the current FPM technique is not able to show that crowd workers create one piece of the overall list of ideas within one week. Therefore,

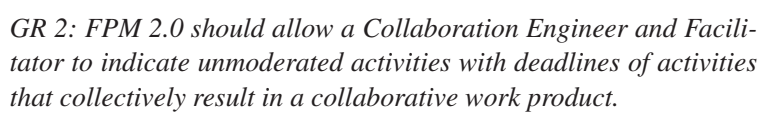

Third, FPM 1.0 is not able to visualize different work environments. For example, crowd workers and employees have different workspaces. In addition, it is possible that workspaces change within a collaborative work practice (e.g., meeting room, shared writing pages). Therefore

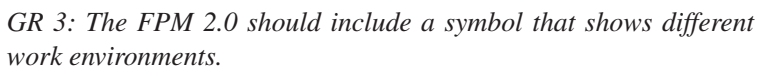

Fourth, FPM 1.0 is not able to visualize external input. For example, the decision-makers need evaluation criteria as external input in order to evaluate the idea concepts. Therefore

GR 4: FPM 2.0 should include symbols that indicate external inputs.

Fifth, FPM 1.0 is not able to visualize parallel processes within a stakeholder group. For example, when different employees have to elaborate on different idea concepts, parallel processes take place.

\section{GR 5 (included after evaluation): FM 2.0 should include symbols that indicate parallel processes.}

\section{General Requirements of Modeling Languages}

Since there are general requirements that arise from new forms of collaboration, the current version of FPM needs a revision. The FPM provides a couple of useful elements that need to be revised and enriched. To be successful in doing so, we need to consider some general standards of modeling languages. According to the evaluation framework of Krogstie [24], there are some meta requirements for modeling languages that need to be considered. Modeling languages are modeler-appropriate in terms of expressing the modeler's knowledge to achieve their goal. In our context, the modeler of the FPM is the Collaboration Engineer. As described in Section II-B, the Collaboration
Engineer uses the FPM for creating an overview/process model of their developed collaborative work practice in the form of a process model that captures their high-level design decisions in order to transfer it to potential facilitators. Therefore

MR 1-Modeler Appropriateness: The FPM 2.0 should offer the CE a toolkit (elements, symbols, rules) to package its high-level design decisions in a process model to design the collaborative work practice.

Modeling languages are participant-appropriate in terms of expressing all the knowledge of the stakeholders that is relevant to the domain. In our context, the users of an FPM that illustrates a collaborative work practice are facilitators (noncollaboration experts). Therefore,

MR 2-Participant Appropriateness: The FPM 2.0 should include intuitive symbols and should not include detailed information that increases the complexity and cognitive load of potential facilitators.

Modeling languages are comprehensibility-appropriate in terms of making sure that the social actors understand the model. In our context, we use the established FPM and revise and extend its elements, symbols, and rules with BPMN 2.0 elements. The value of the original FPM is inherent in its simplicity. Moreover, Frank et al. [24] state that the modeling language should be based on already existing, well-established modeling standards. Therefore,

MR 3-Comprehensibility Appropriateness: The FPM 2.0 should be based on already existing, well-established modeling standards such as the FPM and BPMN 2.0.

\section{First Expert Panel Evaluation}

We close the first design cycle by evaluating our initial challenges and requirements with a qualitative survey as follows.

1) Step 1-Identification of the CE-expert panel: We identified a panel of $14 \mathrm{CE}$-experts from all over the world. CE-experts are those that

a) are used to the body of CE literature;

b) have facilitation expertise;

c) have designed, implemented, and executed collaborative work practices on their own.

Five CE-experts responded to our survey. Table I shows the characteristics of the expert panel.

2) Step 2-Survey preparation: We developed a qualitative survey with the following open-ended questions.

a) Have you used Facilitation Process Models (FPM)?

b) Are there any annoying limitations in the models you use?

c) Have you made any extensions to FPM? We sent the survey by e-mail to the experts.

3) Step 3-CE-expert panel responses and qualitative analysis: The experts have been using FPM models for several years to guide practitioners in the exercise of their collaborative work practices. We used methods of qualitative data analysis, thereby marking all the challenges we found in order to compare the results with our identified challenges and corresponding requirements. This way, we were able to see whether they can confirm our requirements and potentially come up with new ones. 
TABLE I

EXPERT PANEL CHARACTERISTICS

\begin{tabular}{|l|l|l|l|l|l|}
\hline & \multicolumn{1}{|c|}{ Expert 1 } & \multicolumn{1}{|c|}{ Expert 2 } & \multicolumn{1}{|c|}{ Expert 3 } & \multicolumn{1}{|c|}{ Expert 4 } & \multicolumn{1}{|c|}{ Expert 5 } \\
\hline Gender & $\mathrm{f}$ & $\mathrm{f}$ & $\mathrm{m}$ & $\mathrm{m}$ & $\mathrm{f}$ \\
\hline Nationality & Germany & Germany & Germany & United States & Austria \\
\hline Function & Researcher & Researcher & Researcher & Researcher & Researcher \\
\hline $\begin{array}{l}\text { Experience } \\
\text { with Collabo- } \\
\text { ration Engi- } \\
\text { neering in } \\
\text { years }\end{array}$ & $1-5$ years & $5-10$ years & $1-5$ years & $5-10$ years & $5-10$ years \\
\hline
\end{tabular}

4) Step 4-Results of the CE-expert panel: Several experts mentioned that they found no way to model different stakeholder groups with the FPM modeling technique (Challenge 1-Different team compositions). As a potential solution, one expert mentioned to use color coding to mark different stakeholders. Two experts mentioned that there is no way to model individual work such as things like homework (Challenge 2-Unmoderated Activity). Moreover, two experts missed the possibility to visualize parallel processes. One expert mentioned to use additional modeling tools (e.g., BPMN) instead. We coded this statement as a new challenge and added the visualization of parallel processes (Challenge 5Parallel Activities) to our challenges and corresponding requirements.

\section{E. Revised Facilitation Process Model 2.0}

Based on our identified requirements, we enrich the current FPM modeling technique with the well-known standard of BPMN 2.0 elements and our own inventions (see Table II). First, we used the BPMN 2.0 element Pool/Lane that represents different participants or participant types who take part in a process. The pool is a vertical rectangular container that can contain flow objects vertically or horizontally. A lane is a graphical subdivision in a pool that is used to organize and categorize activities within a pool according to a role [9]. FPM 2.0 includes Stakeholder Lanes that allow the collaboration engineer to differentiate between different stakeholders, such as employees and the crowd. Moreover, activities conducted by AI systems can also be modeled as separate lanes [38]. Thus, the FPM 2.0 is able to differentiate between stakeholders or subteams along the activity flow (GR1). Second, we introduce a new symbol in the form of a piece in the puzzle indicating that a moderated activity is interrupted by an Unmoderated Activity. An Unmoderated Activity is characterized by two independent pieces of activities that result in a common output. These subtasks have deadlines so that the ongoing process can continue. The deadlines are depicted below the pieces in the puzzle (GR2).

Third, the Work Environment symbol indicates when activities take place in different work environments (GR3). Fourth, the External Input elements are objects that symbolize an external input for an entire process. FPM 2.0 includes these symbols to assign activity outputs to inputs and indicate an External Input. The text below the elements gives them a name (GR4). Fourth, the BPMN 2.0 element Parallel MI marker marks a task that is to be repeated until a defined condition either applies or ceases to apply. We transferred this element in order to indicate activities that have to be executed multiple times until the output is achieved. FPM 2.0 therefore addresses Parallel Activities (GR5).

The new FPM 2.0 modeling language now provides all the symbols that collaboration engineers and facilitators need to visualize different stakeholders, unmoderated activities, working environments, external input, and parallel processes. Especially in mass collaboration settings such as OI projects, these elements can help collaboration engineers to capture early design decisions and to introduce a new work practice to facilitators of mass collaborations.

\section{F. Application of FPM 2.0}

In the following, we exemplarily illustrate the application of our new FPM 2.0 based on our initial exemplary scenario in order to see if we can capture all the identified deficiencies of the old version of FPM. Again, the collaboration goal is to select the best idea concepts for a new lifestyle traveling brand in an AI-supported collaboration (among decision-makers and employees from the innovation department and potential customers inherent in crowd workers, see Fig. 4).

In the ideation phase, the decision-makers generate an assignment for their employees and external crowd workers. The assignment specifies the categories for which they want to collect new idea concepts. The different stakeholders, i.e., decisionmakers, employees, the crowd, and the AI text-mining system, 
TABLE II

NEW FPM 2.0 ELEMENTS

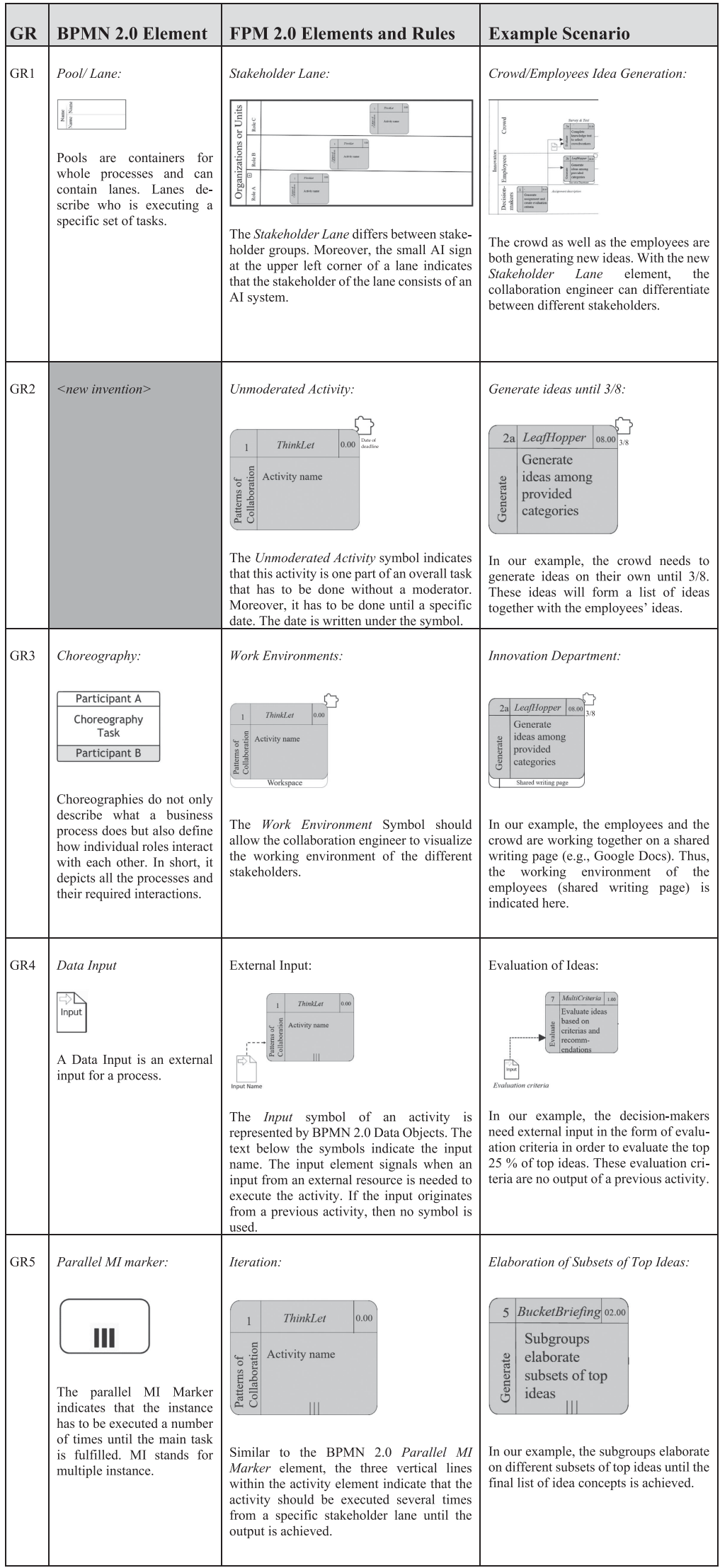


Phase 1: Ideation

Phase 2: Convergence

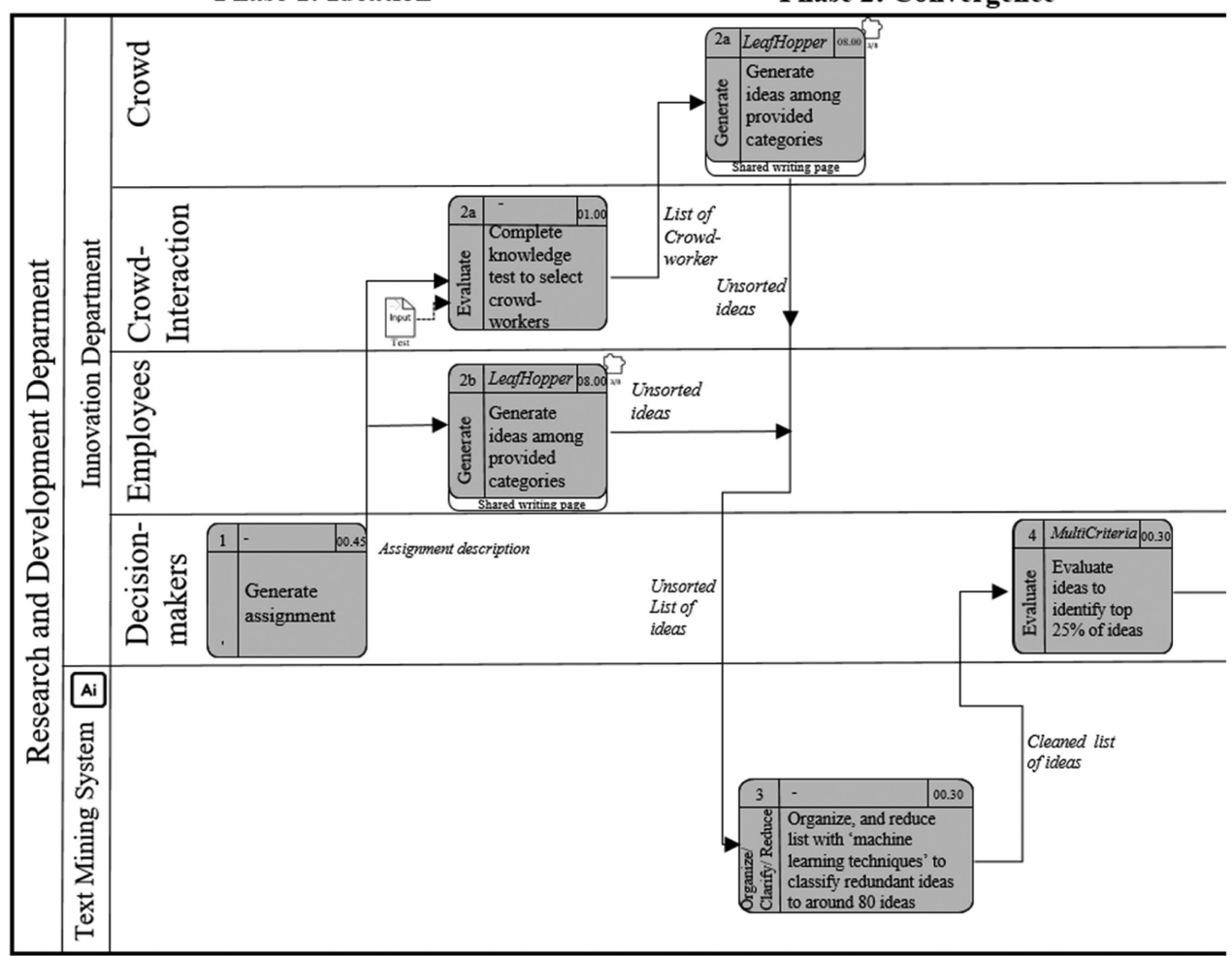

Phase 3: Evaluation

Phase 4: Selection

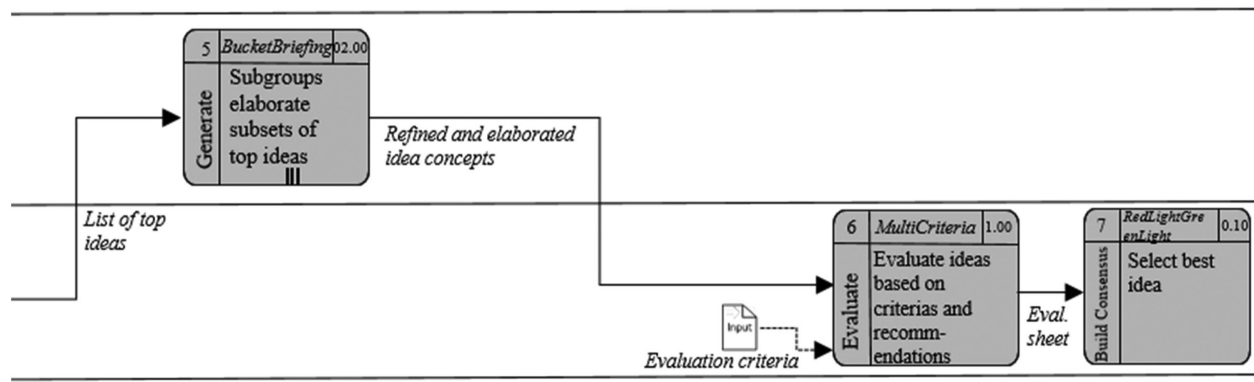

Fig. 4. FPM 2.0 exemplary application based on our initially described scenario. 
TABLE III

SAMPLE CHARACTERISTICS OF EXPERT PANEL

\begin{tabular}{|l|l|l|l|l|l|l|}
\hline & Expert 1 & Expert 2 & Expert 3 & Expert 4 & Expert 5 & Expert 6 \\
\hline Gender & f & f & $\mathrm{m}$ & $\mathrm{m}$ & $\mathrm{m}$ & $\mathrm{m}$ \\
\hline Nationality & Austria & Germany & Germany & $\begin{array}{l}\text { New Zea- } \\
\text { land }\end{array}$ & $\begin{array}{l}\text { United } \\
\text { States }\end{array}$ & Germany \\
\hline Function & $\begin{array}{l}\text { Re- } \\
\text { searcher }\end{array}$ & $\begin{array}{l}\text { Re- } \\
\text { searcher }\end{array}$ & $\begin{array}{l}\text { Pract- } \\
\text { itioner }\end{array}$ & Researcher & $\begin{array}{l}\text { Pract- } \\
\text { itioner }\end{array}$ & $\begin{array}{l}\text { Pract- } \\
\text { itioner }\end{array}$ \\
\hline $\begin{array}{l}\text { Experience } \\
\text { with OI in } \\
\text { years }\end{array}$ & $1-5$ years & 5-10 years & 5-10 years & $15-20$ years & $\begin{array}{l}15-20 \\
\text { years }\end{array}$ & 5-10 years \\
\hline
\end{tabular}

are modeled in a different Stakeholder Lane. In the subsequent activity, employees and external crowd workers generate ideas independently from each other. The Unmoderated Activity symbol with the date $3 / 8$ indicates that the activity of the crowd is a subtask that results in a collaborative product. Moreover, the task is due on $3 / 8$. While the employees can start directly, the crowd workers need to complete a test. Both stakeholders are instructed to complete their task within one week, resulting in a collaborative work product as an unsorted list of idea results. In the convergence phases, convergence activities start. The unsorted list of ideas is delivered to an AI (i.e., text mining system) that uses machine learning techniques to identify and cluster similar ideas into a list of 80 ideas. After that, the AI delivers the cleaned list of ideas to the group of decision-makers. Then, the evaluation phase starts. The decision-makers evaluate the ideas and build a list of the top 20 ideas. Next, the top 20 ideas are split into subsets and are assigned to smaller breakout groups of employees. The Parallel Activities symbol allows the modeler to show that this activity has to be done several times until the desired output is achieved. The breakout groups work in parallel and elaborate the assigned ideas to meaningful idea concepts. The idea concepts constitute the input for the next phase and activity. Finally, the selection phase starts in which the decision-makers evaluate the top 20 idea concepts based on predefined criteria. The External Input symbol indicates that an external input is needed. The predefined evaluation criteria serve as input for the decision. Finally, the decision-makers decide for the best idea concept.

\section{G. Second Expert Panel Evaluation}

We close the second design cycle by evaluating the application of FPM 2.0 based on our scenario as follows.

1) Step 1-Identification of the OI-expert panel: We identified a panel of six OI experts from all over the world. Three of them can be considered as practitioners, since they are experienced in designing OI projects in their companies, and three of them are researchers, since they have conducted OI research for many years. The characteristics of the expert panel are depicted in Table III.
2) Step 2-Survey preparation: We developed a quantitative and qualitative survey in which we showed the evaluators how we implemented FPM 2.0 based on the initial scenario described in Section IV-A. We asked them to rate the usefulness of FPM 2.0 on the basis of design science research evaluation criteria proposed by March and Smith [39]. Moreover, we included the following open-ended questions.

a) Which other techniques are you using for documenting and communicating OI projects?

b) If you were not satisfied with any of the evaluation criteria above, how could we improve FPM 2.0 and its elements?

3) Step 3-CE-expert panel responses and qualitative analysis: We used simple mean and median calculations to get an impression of the overall ratings for every evaluation criterion and analyzed the responses to our open questions in order to identify possible improvements for FPM 2.0.

4) Step 4-Results of the OI-expert panel: The means and medians for every evaluation criterion are depicted in Table IV.

The overall rating for the usefulness of FPM 2.0 as a modeling technique for OI projects can be considered as positive with a significantly higher score compared to the mean of the scale $(p<0.05)$. There are three main evaluation criteria for which evaluators offered suggestions for improvement: completeness, level of detail, and understandability. First, while most of the experts perceive that the FPM 2.0 includes everything that is relevant to model the depicted innovation project, one expert mentioned that FPM 2.0 and its current elements do not consider the handling of subprocesses or preparation activities. Second, evaluators think that the level of detail suits the goals of the modeling technique. However, one expert believes that further details (e.g., notes for the conduction of the activities) should be shown in a separate window. Third, the evaluators believe that FPM 2.0 and its elements are understandable. Nevertheless, one evaluator mentioned that the unmoderated activity marker does not seem to be intuitive and might confuse future users of FPM 2.0. Moreover, one evaluator is not sure if a separate 
TABLE IV

EXPERT PANEl QUANTITATIVE RESUlts

\begin{tabular}{|l|l|l|}
\hline $\begin{array}{l}\text { Evaluation criteria proposed } \\
\text { by March and Smith [41] }\end{array}$ & Mean (1 to 5, 5 is highest) & Median (1 to 5, 5 is highest) \\
\hline Completeness & 3.80 & 4.00 \\
\hline Ease of use & 4.00 & 5.00 \\
\hline Effectiveness & 3.60 & 4.00 \\
\hline Efficiency & 3.60 & 4.00 \\
\hline $\begin{array}{l}\text { Fidelity with real world phe- } \\
\text { nomena }\end{array}$ & 3.60 & 4.00 \\
\hline $\begin{array}{l}\text { Generality } \\
\text { Impact on the environment } \\
\text { and on the artifact's users }\end{array}$ & 4.00 & 4.00 \\
\hline Internal consistency & 4.00 & 4.00 \\
\hline Level of detail & 3.60 & 4.00 \\
\hline Operationality & 4.00 & 4.00 \\
\hline Robustness & 4.20 & 4.00 \\
\hline Simplicity & 3.60 & 4.00 \\
\hline Understandability & 4.00 & 4.00 \\
\hline Total & $\mathbf{3 . 8 5}$ & 4.00 \\
\hline
\end{tabular}

lane for AI-initiated activities is really needed and refers to the BPMN automation symbol that indicated when it is an automated activity.

\section{DISCUSSION}

In this article, we report on the development of an updated version of the FPM, which is widely used by CE researchers and practitioners. The main goal of FPM 2.0 is to help people in organizations to successfully design and implement OI projects. According to one of the most comprehensive sample surveys of open innovation adoption among 2840 large firms in Europe and the United States, open innovation continues to be widely practiced in about $80 \%$ of the companies [5]. However, interviewed managers state that they are not satisfied with the routines and metrics available to them [5]. Similarly, many researchers argue that open innovation is currently not structured enough and requires a more formal approach for managing various inflows and outflows of open innovation projects [40], [41]. The literature provides little assistance in this regard and interest in modeling techniques to support innovation is rapidly increasing [42]. Our current understanding of a firm's processes for participating in OI projects is scattered and limited and OI has not been sufficiently formalized [6]. It can be argued that managers could seek inspiration from case studies (e.g., [43]), but such cases usually focus on a single project, which makes it difficult to extract transferable insights. For example, Kirschbaum [43] accompanied a multinational life sciences and performance materials company when it was opening up its innovation process. During the process, he detected different management styles needed along the different phases of an OI project. Furthermore, several past studies have adopted a broader perspective focusing on the firm or business unit (e.g., [44], [45]). For example, Laursen and Salter [44] investigated the way organizations search for new ideas and determined that firms who have wide and deep open search strategies tend to be more innovative. These insights are useful but not fine-grained enough for managers to initialize and manage open innovation projects. In order to address some of the challenges in the design and management of OI projects, we need an unambiguous modeling technique to capture OI processes. 
Trying to address this need, our article makes several theoretical contributions and practical implications.

\section{A. Theoretical Contribution}

First, the current FPM technique suffers from several shortcomings that make it hard to impossible to capture mass collaboration processes such as OI settings. Compared to the original FPM, the FPM 2.0 technique is arguably a superior modeling technique for $\mathrm{CE}$ and $\mathrm{OI}$ researchers to design and report OI projects, with a special focus on outside-in OI endeavors. FPM 2.0 allows CE and OI researchers to be more precise and more systematic in their designs and tackle a broader variety of mass collaboration settings than previously possible. Furthermore, successful OI endeavors can-if modeled using FPM 2.0- be easily reused for structurally comparable OI processes to increase their probability for success. Second, for CE researchers, FPM 2.0 is opening possibilities to address process design issues in contexts that traditionally have not been covered by CE, such as OI processes. Third, for OI researchers, FPM 2.0 can serve as a foundation to design better and reproducible outside-in OI processes that might lead to more effective collaboration processes [28]. Fourth, FPM 2.0 further provides a stronger basis for researchers to report on alternative designs and compare them. A structured and comprehensive modeling technique is a necessity to allow for a detailed and meaningful evaluation of alternative open innovation process designs. Finally, researchers in the field of OI are now able to systematically visualize the process that they followed when investigating or implementing an outside-in OI endeavor, such as an idea competition. This will help them to supervise their project and facilitate the review of their study's execution as well as strengthen its replicability by other researchers.

In sum, our article represents a new modeling technique that strengthens researchers' ability to unambiguously capture OI processes and thereby increases the ability for these processes to be analyzed, evaluated, and compared.

\section{B. Practical Implications}

This article also has several implications for practice. First, we argue that FPM 2.0 represents a richer yet still easy-to-use modeling technique. FPM 2.0 models are expected to be easy to communicate to any stakeholder involved in a collaboration process. This is also shown by our second evaluation with OI experts, who mostly understand how to use FPM 2.0. The application of FPM 2.0 of OI experts to design outside-in OI processes should be the aim of future research, both in the context of developing a process design as well as using FPM 2.0 models to support training practitioners in the execution of a process. Second, innovation departments can now use this modeling language to document the described kind of OI processes and to reuse OI processes, or at least parts of them that have proven to be successful.

\section{CONCLUSION}

In our article, we identified five distinct challenges of modeling OI settings and derived requirements for an updated version of the technique. We selected elements from the BPMN 2.0 standard that were incorporated into the FPM technique to meet these requirements, resulting in FPM 2.0. In itself, FPM 2.0 is different from the BPMN 2.0 process model technique in that it only includes the elements that are required for a CE modeling effort and expands on some elements to include aspects that are specific to CE, such as a designation for an activity's resulting pattern of collaboration and the thinkLet used to execute the activity. We further evaluated the identified challenges and requirements with a CE expert panel and applied and evaluated FPM 2.0 using an example OI scenario.

A number of limitations have to be considered with respect to this article. First, the scope of the article is limited to "outside-in" OI processes and is, thus, not generalizable for all other kinds of OI endeavors. Future research should investigate whether FPM 2.0 can also be beneficial for other OI settings (e.g., "inside-out OI processes"). For example, FPM 2.0 could also be useful in designing collaborations between companies and their own innovation spin-offs. Second, the list of challenges with the current FPM is based on an exemplary scenario. While this scenario addresses the most prevalent challenges that CE researchers have encountered in recent years, they may not be comprehensive. While we attempted to include a rich and holistic example, more cases will be needed to further determine the broad applicability and completeness of the FPM 2.0 technique. Future research is recommended to develop a structured overview of "outside-in" OI settings that FPM 2.0 has to be able to model. Based on such an overview, additional challenges may be uncovered. Third, the quality of FPM 2.0 has yet to be determined in practice. To this end, we recommend a portfolio of assessment studies. For example, we explain to people how the collaboration process works with either an FPM 1.0 model or an FPM 2.0 model. After that, we ask the people about details/the exact process of the OI endeavor. More than that, designers could be trained in the use of FPM 2.0 and could be given several collaborative situations for which they have to produce a process design. These designs could be evaluated according to quality and the designers' perceptions of the ease of use and completeness of the FPM 2.0 technique. Also, existing collaboration processes in use in organizations could be modeled using FPM 2.0 to determine whether a complete and correct representation of these processes can be created.

\section{REFERENCES}

[1] E. Seltzer and D. Mahmoudi, "Citizen participation, open innovation, and crowdsourcing: Challenges and opportunities for planning," J. Planning Literature, vol. 28, no. 1, pp. 1-16, 2013.

[2] H. Shimazu and S. Koike, "KM2. 0: Business knowledge sharing in the Web 2.0 age," NEC Tech. J., vol. 2, no. 2, pp. 50-54, 2007.

[3] I. Seeber, G.-J. de Vreede, R. Maier, and B. Weber, "Beyond brainstorming: Exploring convergence in teams," J. Manage. Inf. Syst., vol. 34, no. 4, pp. 939-969, 2017.

[4] T. de Vreede et al., "A theoretical model of user engagement in crowdsourcing," in Proc. Int. Conf. Collaboration Technol., Oct. 2013, pp. 94-109.

[5] H. Chesbrough and S. Brunswicker, Managing Open Innovation in Large Firms. Stuttgart, Germany: Fraunhofer Verlag, 2013.

[6] H. Chesbrough, C. Lettl, and T. Ritter, "Value creation and value capture in open innovation," J. Prod. Innov. Manage., vol. 35, no. 6, pp. 930-938, 2018.

[7] C. Alexander, S. Ishikawa, M. I. Silverstein, J. R. Ramió, M. Jacobson, and I. Fiksdahl-King, "A pattern language," Gustavo Gili, Barcelona, Spain, 1977. 
[8] G. J. de Vreede and R. O. Briggs, "Collaboration engineering: Reflections on 15 years of research \& practice," in Proc. 51 st Hawaiian Int. Conf. Syst. Sci., Jan. 2018, pp. 410-419.

[9] Object Management Group, Needham, MA, USA, Notation, 2013.

[10] R. O. Briggs, G.-J. de Vreede, and J. F. Nunamaker Jr, "Collaboration engineering with ThinkLets to pursue sustained success with group support systems," J. Manage. Inf. Syst., vol. 19, no. 4, pp. 31-64, 2003.

[11] J. M. Leimeister, Collaboration Engineering: IT-Gestützte Zusammenarbeitsprozesse Systematisch Entwickeln und Durchführen. Berlin, Germany: Springer, 2014.

[12] R. O. Briggs et al., "A six-layer model of collaboration," in Advances in Management Information Systems, Routledge, New York, 2014, pp. 221-228.

[13] G. L. Kolfschoten and G.-J. de Vreede, "A design approach for collaboration processes: A multimethod design science study in collaboration engineering," J. Manage. Inf. Syst., vol. 26, no. 1, pp. 225-256, 2009.

[14] G. L. Kolfschoten, R. O. Briggs, G.-J. de Vreede, P. H. M. Jacobs, and J. H. Appelman, "A conceptual foundation of the thinkLet concept for collaboration engineering," Int. J. Human-Comput. Stud., vol. 64, no. 7, pp. 611-621, 2006.

[15] G.-J. Vreede, R. Briggs, and A. Massey, "Collaboration engineering: Foundations and opportunities: Editorial to the special issue on the journal of the association of information systems," J. Assoc. Inf. Syst., vol. 10, no. 3, pp. 121-137, 2009.

[16] B. Boehm, P. Grunbacher, and R. O. Briggs, "Developing groupware for requirements negotiation: Lessons learned," IEEE Softw., vol. 18, no. 3, pp. 46-55, May/Jun. 2001.

[17] P. Grünbacher et al., "Making every student a winner: The WinWin approach in software engineering education," J. Syst. Softw., vol. 80, no. 8, pp. 1191-1200, 2007.

[18] G. J. de Vreede, "Two case studies of achieving repeatable team performance through collaboration engineering," MIS Quart., vol. 13, no. 2, pp. 115-129, 2014.

[19] G.-J. de Vreede, A. Fruhling, and A. Chakrapani, "A repeatable collaboration process for usability testing," in Proc. 38th Annu. Hawaii Int. Conf. Syst. Sci., Jan. 2005, p. 46.

[20] P. B. Lowry, T. Roberts, D. L. Dean, and G. M. Marakas, "Toward building self-sustaining groups in PCR-based tasks through implicit coordination: The case of heuristic evaluation," J. Assoc. Inf. Syst., vol. 10, no. 3, pp. 170-195, 2009.

[21] V. Grinsven, J. de Vreede, and Gert-Jan, "Addressing productivity concerns in risk management through repeatable distributed collaboration processes," in Proc. 36th Annu. Hawaii Int. Conf. Syst. Sci., 2003, pp. 10-19.

[22] M. Noor, P. Grünbacher, and R. O. Briggs, "A collaborative approach for product line scoping: A case study in collaboration engineering," in Proc. 25th Conf. IASTED Int. Multi-Conf., 2007, pp. 216-223.

[23] T. Giesbrecht, G. Schwabe, and B. Schenk, "Service encounter thinklets: How to empower service agents to put value co-creation into practice," Inf. Syst. J., vol. 27, no. 2, pp. 171-196, 2017.

[24] J. Krogstie, "Evaluating UML using a generic quality framework," in $U M L$ and the Unified Process. Hershey, PA, USA: IGI Global, 2003, pp. 1-22.

[25] A. Grosskopf, G. Decker, and M. Weske, The Process: Business Process Modeling Using BPMN. Tampa, FL, USA: Meghan Kiffer Press, 2009.

[26] T. Allweyer, A. Lübbe, and S. Schnägelberger, "BPM toolmarktmonitor 2015. marktübersicht zu BPM systemen für prozessautomatisierung. ed. v. BPM \& O. BPM\&O,” 2015. [Online]. Available: http://www. bpmo.de/bpmo/opencms/de/know_how/content/toolauswahl/index.html. Accessed on: Jan. 21, 2016

[27] H. W. Chesbrough, Open Innovation: The New Imperative for Creating and Profiting From Technology. Brighton, MA, USA: Harvard Bus. Press, 2006.

[28] O. Gassmann and E. Enkel, in Proc. R\&D Manage. Conf., 2004, pp. 213221.

[29] F. Piller, K. Möslein, C. Ihl, and R. Reichwald, Interaktive Wertschöpfung kompakt: Open Innovation, Individualisierung und neue Formen der Arbeitsteilung. New York, NY, USA: Springer-Verlag, 2017.

[30] M. Bogers et al., "The open innovation research landscape: Established perspectives and emerging themes across different levels of analysis," Ind. Innov., vol. 24, no. 1, pp. 8-40, 2017.

[31] I. Mergel, "Opening government: Designing open innovation processes to collaborate with external problem solvers," Social Sci. Comput. Rev., vol. 33, no. 5, pp. 599-612, 2015.

[32] A. R. Hevner, "A three cycle view of design science research," Scand. J. Inf. Syst., vol. 2, no. 19, pp. 87-92, 2007.
[33] S. Gregor, "The nature of theory in information systems," MIS Quart., vol. 30, no. 3, pp. 611-642, 2006.

[34] S. Gregor and A. R. Hevner, "Positioning and presenting design science research for maximum impact," MIS Quart., vol. 37, no. 2, pp. 337-355, 2013.

[35] M. Dodgson, D. Gann, and A. Salter, "The role of technology in the shift towards open innovation: The case of Procter \& Gamble," $R \& D$ Manage. vol. 36, no. 3, pp. 333-346, 2006.

[36] V. Mrass, C. Peters, and J. M. Leimeister, "New work organization through crowdworking platforms-A case study," in Proc. Zukunftsprojekt Arbeitswelt 4.0, 2016, pp. 1-4.

[37] I. Seeber et al., "Machines as teammates: A collaboration research agenda," in Proc. Hawai Int. Conf. Syst. Sci., 2018, pp. 420-429.

[38] I. Seeber et al., "Machines as teammates: A research agenda on AI in team collaboration," Inf. Manage., 2019, Art. no. 103174.

[39] S. T. March and G. F. Smith, "Design and natural science research on information technology," Decis. Support Syst., vol. 15, no. 4, pp. 251-266, 1995.

[40] U. Lichtenthaler and E. Lichtenthaler, "A capability-based framework for open innovation: Complementing absorptive capacity," J. Manage. Stud., vol. 46, no. 8, pp. 1315-1338, 2009.

[41] O. Gassmann, E. Enkel, and H. Chesbrough, "The future of open innovation," R\&D Manage., vol. 40, no. 3, pp. 213-221, 2010.

[42] B. Scozzi, C. Garavelli, and K. Crowston, "Methods for modeling and supporting innovation processes in SMEs," Eur. J. Innov. Manage., vol. 8 , no. 1, pp. 120-137, 2005.

[43] R. Kirschbaum, "Open innovation in practice," Res. Technol. Manage., vol. 48 , no. 4, pp. 24-28, 2005.

[44] K. Laursen and A. Salter, "Open for innovation: The role of openness in explaining innovation performance among U.K. manufacturing firms," Strategic Manage. J., vol. 27, no. 2, pp. 131-150, 2006.

[45] H. Chesbrough and S. Brunswicker, "A fad or a phenomenon?: The adoption of open innovation practices in large firms," Res. Technol. Manage., vol. 57, no. 2, pp. 16-25, 2014.

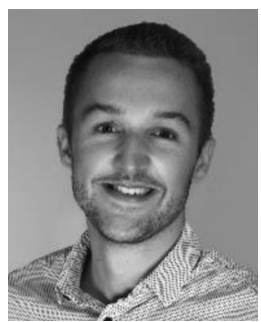

Rainer Winkler is currently working toward the $\mathrm{Ph} . \mathrm{D}$. degree in business innovation with the Institute of Information Management, University of St. Gallen, St. Gallen, Switzerland.

His research focuses on collaboration engineering and the use of smart personal assistants in education. In specific, he is interested in investigating the full potential of smart personal assistants and similar learning technologies to enhance the learning success of students at different educational levels.

Mr. Winkler presented his research at international conferences such as International Conference on Information Systems, Annual Meeting of the Academy of Management, ACM CHI Conference on Human Factors in Computing Systems or Hawaii International Conference on System Science.

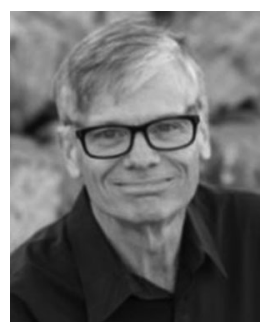

Robert O. Briggs received the Ph.D. degree in information systems from the University of Arizona, Tucson, AZ, USA, in 1994.

His research focuses on the cognitive foundations of collaboration and he uses his findings to create new collaboration systems and new collaborative organizational work practices. He is a co-founder of Collaboration Engineering co-inventor of the ThinkLets design pattern language, co-developer of the Six-layer model of Collaboration. He has published more than 250 peer-reviewed manuscripts related to economic, social, political, cognitive, emotional, and technological aspects of collaboration. Working with colleagues, he has derived theories to explain and predict group productivity, creativity, idea quality, consensus, willingness to commit, willingness to change, and satisfaction responses. He is the inventor of Computer Assisted Collaboration Engineering. 


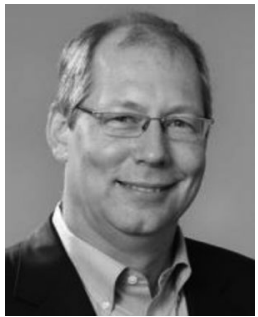

Gert-Jan de Vreede received the Ph.D. degree from Delft University of Technology, Delft, The Netherlands, in 1995.

$\mathrm{He}$ is an Associate Dean for Research and Professor of Information Systems and Decision Sciences, Muma College of Business, University of South Florida, Tampa, FL, USA. He is the co-founder of Collaboration Engineering as a scholarly discipline and co-inventor of the thinkLets design pattern language. His research focuses on crowdsourcing, collaboration engineering, convergence, and creativity.

Dr. Vreede has published his research in Journal of Management Information Systems, Journal of the Association for Information Systems, Information \& Management, Communications of the ACM, MIS Quarterly Executive, Small Group Research, and many others.

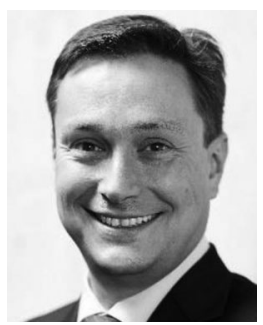

Jan Marco Leimeister received the Ph.D. degree from the University of Hohenheim, in 2004.

He is a Full Professor and Director with the Institute of Information Management, University of St. Gallen, St. Gallen, Switzerland. He is also a Full Professor and Director of the Research Center for Information System Design (ITeG), University of Kassel, Kassel, Germany. His research focuses on digital business, digital transformation, service engineering and service management, crowdsourcing, digital work, collaboration engineering and IT innovation management. He runs research groups and projects that are funded by the European Union, German Ministries, DFG, various foundations or industry partners. He teaches in several Executive Programs.

Prof. Leimeister's research and teaching has received various awards. The business ranking of the renowned German magazine "Wirtschaftswoche" sees Professor Leimeister among 2.824 researchers from Germany, Austria, and Switzerland (based on publications in journals) on the 4th place in 2014-2018 and on the 8th place regarding lifetime achievement. He is a member of the committees of several high-ranking IS journals, for example, an Associate Editor of the European Journal of Information Systems (EJIS), Senior Editor of the Journal of Information Technology (JIT), member of the editorial board of the Journal of Management Information Systems (JMIS) and member of the department editorial board and Section Editor of the Journal Business \& Information Systems Engineering (BISE).

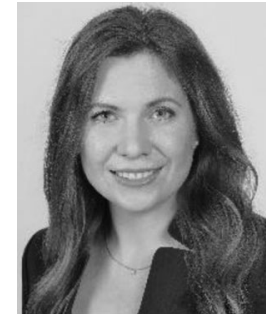

Sarah Oeste-Reiss received the doctoral degree from the University of Kassel, Kassel, Germany, in 2017.

She is a Postdoctoral Researcher with the Research Center for Information Systems Design (ITeG), University of Kassel. Her research focuses on collaboration engineering, socio-technical systems, peer learning and collaborative interactive learning. Her research interests include developing, implementing, and evaluating techniques for designing socially acceptable collaborative work practices with human and nonhuman teammates.

Ms. Oester-Reiss' has published her research in journals such as Information \& Management and Informatik Spektrum as well as published and presented her research at international conferences such as International Conference on Information Systems, Annual Meeting of the Academy of Management or Hawaii International Conference on System Science.

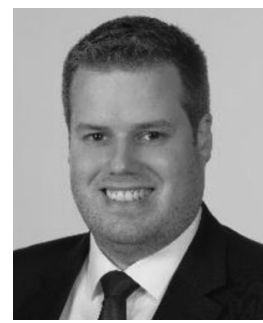

Matthias Söllner received the Ph.D. degree from the University of Kassel, in 2013.

$\mathrm{He}$ is a Full Professor and Chair of Information Systems and Systems Engineering as well as the Director of the Research Center for IS Design (ITeG), University of Kassel, Kassel, Germany. His research focuses on understanding and designing successful digital innovations in domains such as higher education, vocational training and collaboration between humans and machines. He has authored more than 100 scientific publications.

Mr. Söllner's research has been published in many journals such as MIS Quarterly (MISQ, Research Curation), Journal of Information Technology (JIT), European Journal of Information Systems (EJIS), Academy of Management Learning and Education (AMLE), and Business \& Information Systems Engineering (BISE) and presented at conferences such as the International Conference on Information Systems (ICIS), the European Conference on Information Systems (ECIS), the ACM CHI Conference on Human Factors in Computing Systems (CHI), and the Academy of Management Annual Meeting. A recent ranking of more than 2800 business professors in the German-speaking area lists him as \#68 in terms of research output between 2014 and 2018. 